\title{
Measuring Crustal Lg-Waves Attenuation in the Northern Part of Africa
}

\author{
Adoum Issak ${ }^{1}$, Christian Camerlynck ${ }^{2}$ \\ ${ }^{1}$ Faculté des Sciences Exactes et Appliquées, N’Djamena, Tchad \\ ${ }^{2}$ Sorbonne Universités, UPMC Univ Paris 6, Paris, France \\ Email: isacusfr@yahoo.fr
}

Received 7 March 2016; accepted 21 May 2016; published 24 May 2016

Copyright (C) 2016 by authors and Scientific Research Publishing Inc.

This work is licensed under the Creative Commons Attribution International License (CC BY). http://creativecommons.org/licenses/by/4.0/

(c) (i) Open Access

\begin{abstract}
Lg-waves propagate over long distances in the northern part of Africa and are recorded on the seismic station located close to Abeche (Chad). We have applied the well-known coda analysis method developed by Aki and Chouet [1] to study the Lg-wave anelastic attenuation in this area. We found a frequency dependence: $Q(f)=(650 \pm 34) f^{(0.77 \pm 0.2)}$. This result shows an average value of $Q_{0}\left(Q_{0} \approx 650\right)$ for earthquakes occurred in tectonic areas as the East African Rift system, Turkey, Greece and Red Sea. The higher value of $Q_{0}\left(Q_{0} \approx 800\right)$ is obtained for the event occurred in the middle of the stable plate close to the Tamanrasset (TAM) station in Algeria.
\end{abstract}

\section{Keywords}

\section{Lg-Wave Attenuation, Coda, Q Factor, North Africa}

\section{Introduction-Objectives}

Attenuation of regional seismic waves has been studied for years from various points of view including theoretical researches and numerous applied researches in various geophysical environments. Among these studies, Lg-waves have often been studied in order to characterize continental crust, because these wavetrains are often those which carry the most part of the seismic energy. Resulting from both theoretical and observational studies, it is now widely recognized that attenuation of Lg-waves can be represented by two terms:

- The first one only represents the conservation of energy as a function of distance from the source. Thereby, this geometrical attenuation is simply represented by a decaying function of distance: $D^{-\gamma}$ characterized by a unique value $\gamma$.

- The second one represents all the effects of inelastic attenuation, such as energy loss or energy redistribution such as scattering. This term is represented by a function of distance and frequency, controlled a quality fac- 
tor $Q$, which appears to also depend on frequency: $Q(f)=Q_{0} f^{\alpha} \quad$ [2] [3].

Aki (1969) [4] was the first researcher who observed that the seismic Lg-coda could be fruitful to study this quality factor, even by the use of a unique station. From this key study, numerous theoretical studies have been conducted, in particular to try to separate the two origins of inelastic attenuation. This is still a difficult problem, because the theoretical models are very similar. Nevertheless, some authors [5]-[7] have shown using simulation that the early part of the coda is mainly controlled by scattering attenuation, and the late coda is controlled by intrinsic attenuation. Also, observations of Lg-codas have been used to measure the Lg Q-factor in various crustal structures. As a general rule, in tectonic areas, $Q_{0}$ can be less than 100 , and strongly depends on frequency with $\alpha$ close to 1 [8] but in the opposite, in stable areas such as cratons, $Q_{0}$ can be as high as one or 2000 [2] [3] and slightly depends on frequency with $\alpha$ nearly equal to 0.1 . Due to an evident lack of seismicity, and consequently often a lack of stations, in theses stable areas, the $Q$ factor is not documented as well as in tectonic areas. In particular, in North Africa, most of the studies are carried out on the borders of the continent:

- Using seismic networks in Spain and Morocco, [9] had established a map of the propagation efficiency of Lg and Sn waves between the north of Africa and the south of Europe;

- [8] proposed a tomography of Lg wave attenuation from Turkey to Arabia, leading to strong variations of the quality factor, less than 100 in the western and eastern parts of Turkey, and between 600 and 800 in the Arabian plate;

- The East African Plateau had been studied by [10] who had tried to separate intrinsic and scattering $Q$, leading to $Q_{I}$ between 300 and 600, and $Q_{S}$ between 1000 and 2000;

- Finally, in the south-west, in the area of Mount Cameroon, [11] used a local network and the local seismicity which is detected to study attenuation close to the volcano: they found a very low attenuation: $Q(f)=65 f$.

From 2007, a broadband seismic station has been installed in Chad close to the city of Abeche in the eastern part of the country, and is operated by the University of N'Djamena. Recording well developed Lg-wavetrains generated by earthquakes located in the tectonic areas surrounding the north of Africa, this station can be efficiently used to study the Lg Q-factor in this wide stable area. In the following, we successively present the used dataset, the processing method and finally discuss the results.

\section{Data}

The seismic station is ideally situated in the middle of the Nubian plate, which is mainly composed of different cratons and various old geological features, their story beginning during the proterozoic era. The oldest Archean cratons in Africa (West Africa, Congo and Kalahari) are separated by more weak grounds [12] which exhibit a little seismicity, such as the Sirt basin, the North of Egypt [13] and the volcanic line of mount Cameroon [14]. A little seismic activity is also found along the coast line and along the passive Atlantic margin. Not yet fully understood, this seismicity cannot be explained by the velocity inside the Nubian plate (less than $0.6 \mathrm{~mm} / \mathrm{year}$ [15]: much lower than the velocities which can be observed on the edges of the Nubian plate: the convergence velocity between Nubia and Eurasia is close to $5 \mathrm{~mm} / \mathrm{year}$, and can reach up to $25 \mathrm{~mm} /$ year at the south of the Hellenic arc). To the east, Nubia is going away of Arabia at roughly $20 \mathrm{~mm} /$ year [16] and the divergence velocity through the East African Rift ranges from 6 to $3 \mathrm{~mm} /$ year from North to South [15] [17].

This situation explains that the events recorded by the ABC (Abeche) seismic station are mainly located far from the station, more precisely at distances greater than $1700 \mathrm{~km}$ (Table 1, Figure 1). Nevertheless, due to a very low seismic noise, as shown by Figure 2, most of them have developed a well-defined Lg wave train followed by a long duration coda, as shown by the top part of Figure 3. From all these events, we have selected those for which an Lg-wavetrain can be clearly identified. These events are shown by colored dots on Figure 1, color representing magnitude. Then, it appears that some seismic areas cannot be investigated, due to the lack of Lg waves such as the events located south of Italy for which the path travels through the oceanic crust lying between Italy and Africa, which extends also a bit between Greece and Africa. Finally, some events occurred off the western coast of Africa near Morocco; these are low magnitude events, very far from our station, which does not record any available coda.

Furthermore, the special case of the event located in south Algeria, close to the city of Tamanrasset, is of major interest. This mb 4.2 event clearly occurs in a very stable area; it is well recorded in the ABC station as shown by Figure 3. Fortunately, a seismic station, operated by the GeoScope French institute, is located close to the city. The recorded data show a very nice record of this event, as shown by the bottom part of Figure 3. This record 


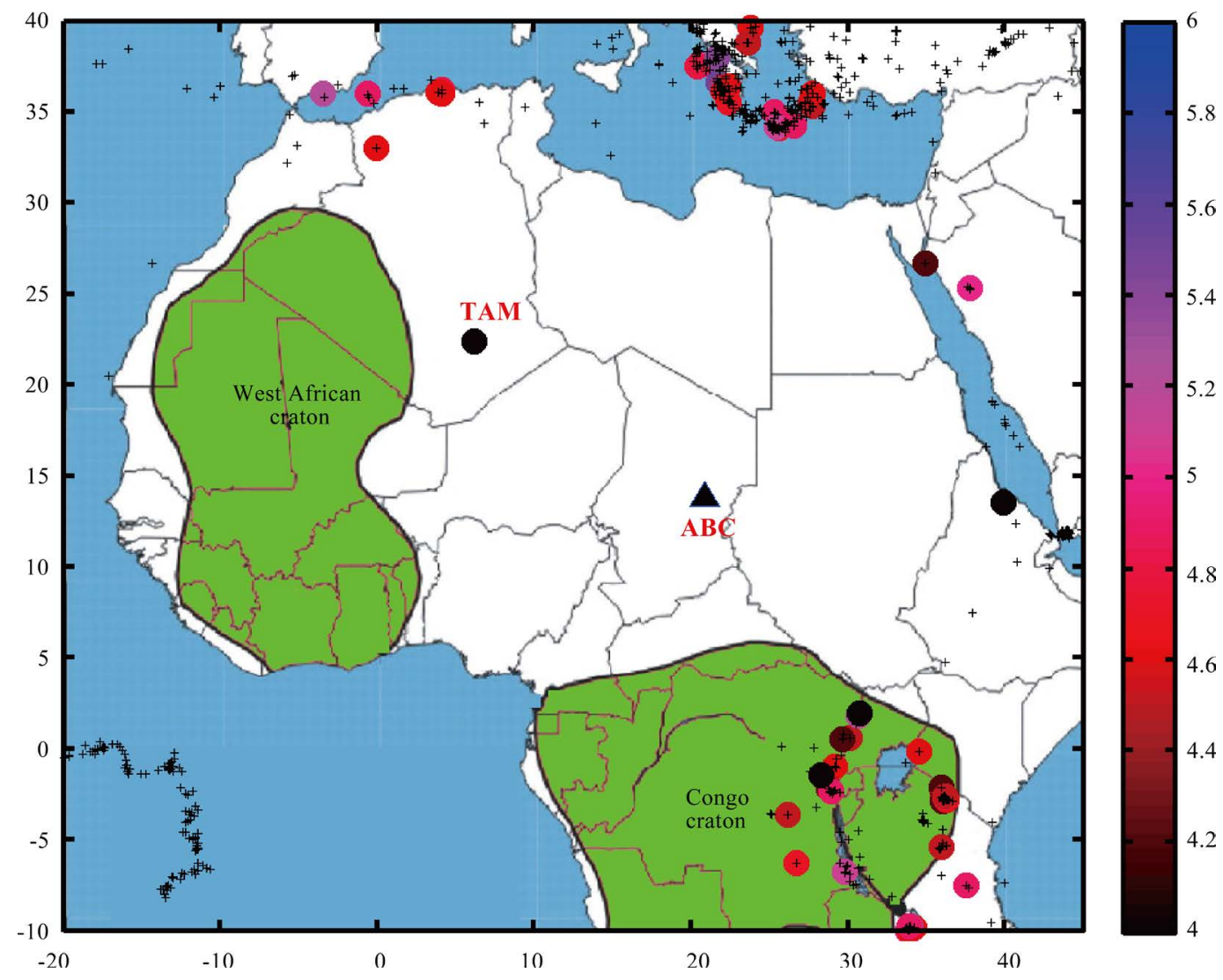

Figure 1. Geographical distribution of the studied events (circles) and Chad station ABC (diamond) displayed on a map of Africa; black little crosses indicate the natural seismicity (magnitude greater than 4) during the studied timeframe.

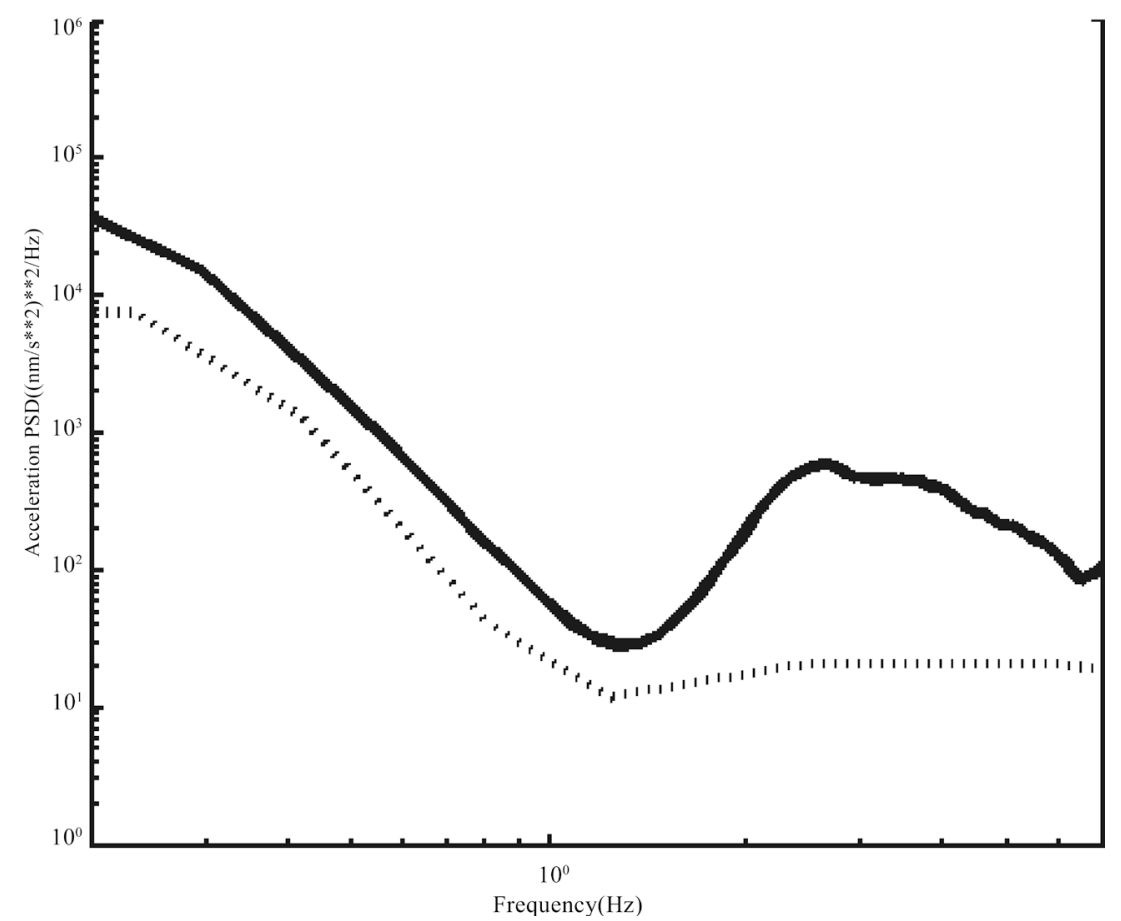

Figure 2. Averaged (median) background seismic noise for ABC station (black line), compared with the Peterson's noise model (NLNM, 1993) [18] (dotted line). 

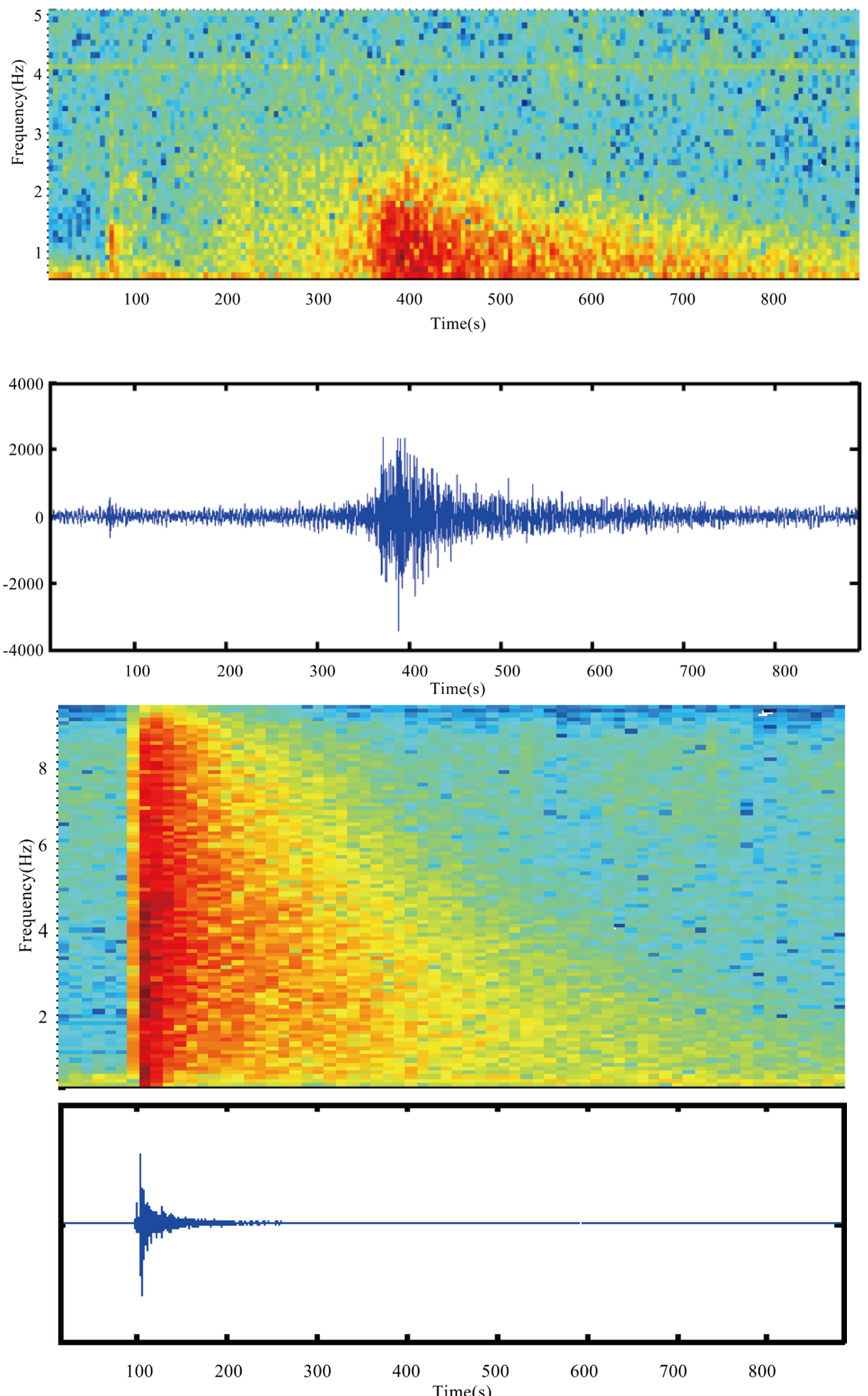

Figure 3. Records and time-frequency distribution of energy for the Tamanrasset event; top: Chad station (ABC), bottom: Tamanrasset station (TAM). 
exhibits a well developed coda ranging at least 600 s, very fruitful for coda-Q measurement.

\section{Processing}

As described in the introduction, we have used the original model of coda decay, proposed by [4] in which the amplitude is represented by a function of frequency and time as follows:

$A(f, t)=C(f) t^{-\gamma} \exp \left(-2 \pi f t /\left(2 Q_{c}(f)\right)\right)$. In this equation, $C(f)$ is the source term, $\gamma$ is the geometrical attenuation and $Q_{c}$ characterises the effects of inelasticity. For each frequency band centered around frequency $f$, the logarithm of the envelope of the filtered coda, computed by a smoothed Hilbert transform, is fitted by a straight line, the slope of which representing the $Q_{c}$ factor for frequency $f$ (Figure 4).

The frequency bands are organised by a logarithmic scale, covering the range $[0.1 ; 5] \mathrm{Hz}$. However, depending on the events, the available frequency bands are limited for most of them to the $[0.5 ; 2] \mathrm{Hz}$ band.

Finally, for each event we compute the frequency dependency of $Q_{c}\left(Q(f)=Q_{0} f^{\alpha}\right)$, as shown by Figure 5, in which the retained values of $Q$ are chosen manually before computing the linear regression.

\section{Results}

\subsection{Estimating the Stability of the Results}

In order to evaluate the stability of the processing, we have selected 6 events which occurred in the same area (south of Kenya) at a distance of roughly $3000 \mathrm{~km}$ from the station. These events occurred the same day (i.e. December 6, 2009), and their magnitudes range from 4.5 to 5.0. Table 1 gives the results in terms of $Q_{0}$ and $\alpha$ coefficients. It shows that the $Q_{0}$ factor is more stable (i.e. $718 \pm 7$ ) than (i.e. $0.6 \pm 0.1$ ), which can be explained by the low range of available frequencies.

\subsection{Global and Regional Results}

The results for the global dataset (namely 70 events) are presented on Figure 6 by a color scale. In order to
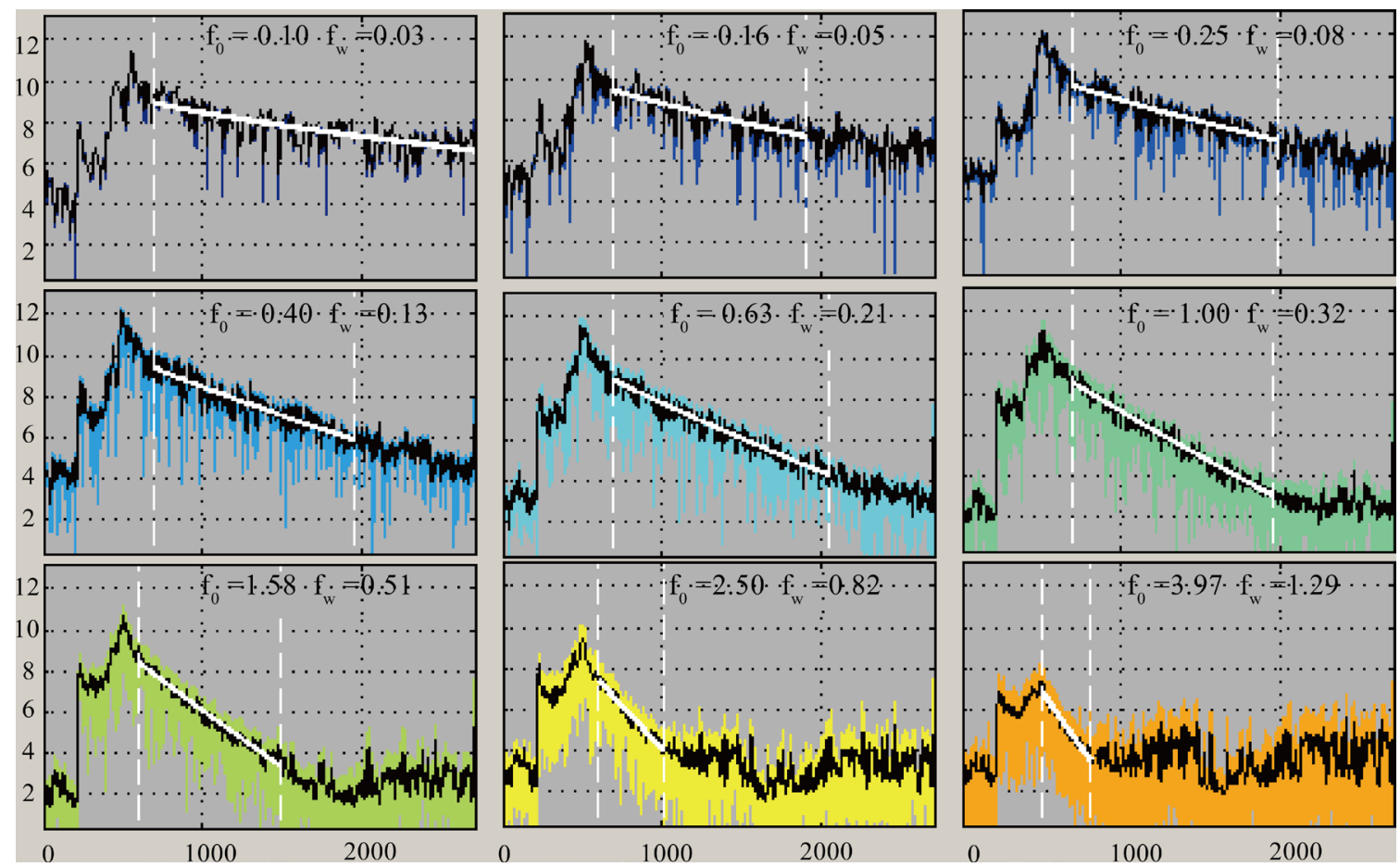

Figure 4. For each frequency band, centered on the $f_{0}$ frequency displayed at the top of each plot, the logarithm of the coda envelope is represented by a color curve and the smoothed coda by a black curve; the white line, delimited by the vertical dashed lines, is the portion of coda which is used for computing the $Q$ value. 


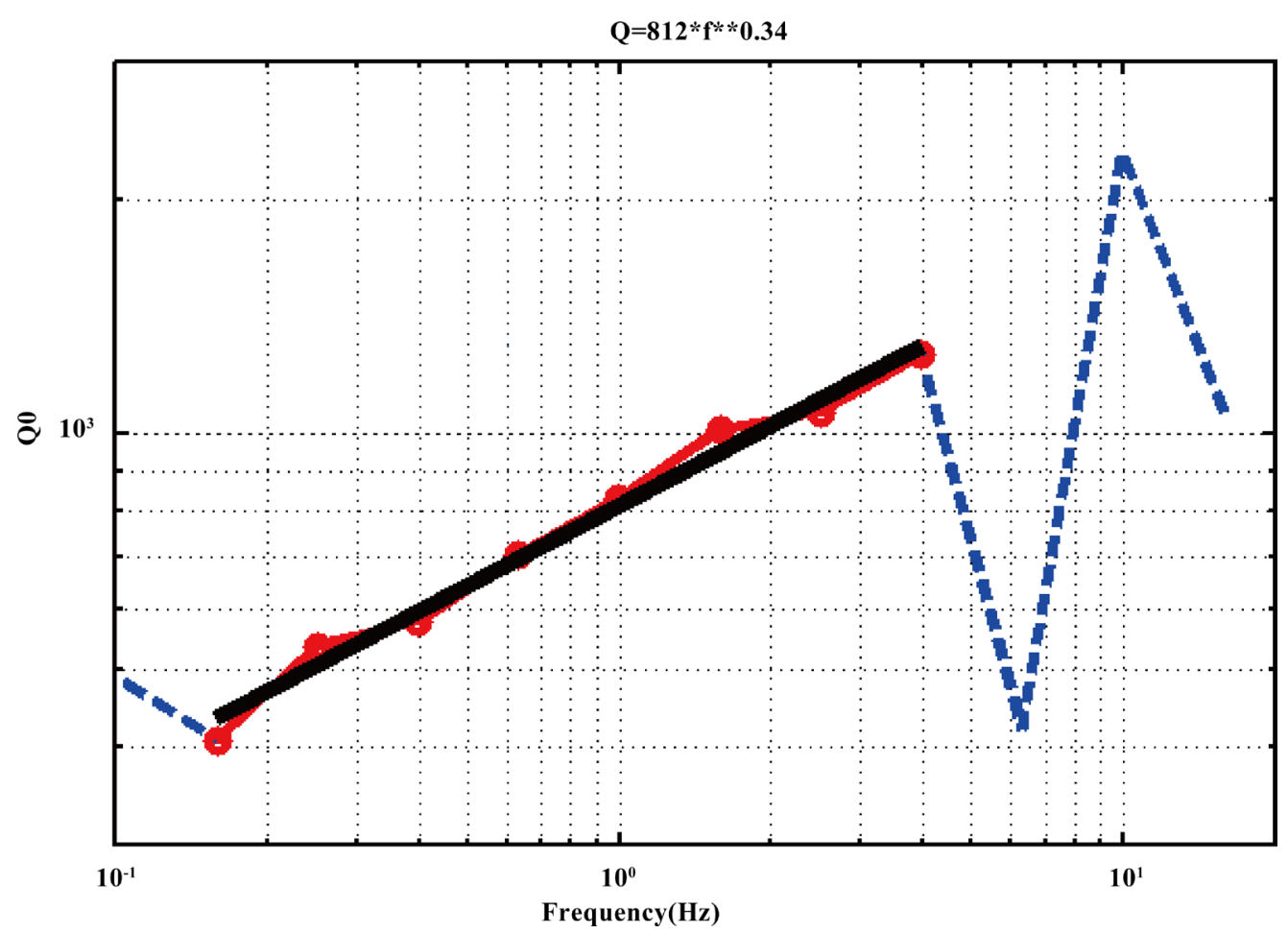

Figure 5. Final estimation of $Q_{c}$ factor: the red circles are the $Q_{c}$ estimated by the fit of the linear part of the coda; the black line is the best linear fit of the selected values delimited by the two vertical dashed lines. The blue dots are the $Q_{c}$ values which are not selected.

Table 1. Results obtained for 6 events located close to one another showing the dispersion of the results.

\begin{tabular}{ccccc}
\hline Date & Origin time & Magnitude $(\mathbf{m b})$ & $\boldsymbol{Q}_{\mathbf{0}}$ & $\boldsymbol{\alpha}$ \\
\hline $06 / 12 / 2009$ & $17: 36: 35$ & 5.0 & 722 & 0.60 \\
$06 / 12 / 2009$ & $18: 29: 14$ & 4.8 & 730 & 0.57 \\
$06 / 12 / 2009$ & $17: 40: 12$ & 4.6 & 717 & 0.40 \\
$06 / 12 / 2009$ & $18: 00: 00$ & 4.7 & 711 & 0.52 \\
$06 / 12 / 2009$ & $17: 58: 14$ & 4.7 & 715 & 0.64 \\
$06 / 12 / 2009$ & $19: 36: 40$ & 4.5 & 718 & 0.38 \\
\hline
\end{tabular}

estimate some regional effects, we have grouped the events by region and computed average values of $Q_{0}$ and $\alpha$; Table 2 presents these values.

Although the values are not very different from one region to others, we can see that the lowest values are obtained for events in Turkey, according to a propagation partly in the oceanic crust in the central Mediterranean Sea, and the highest ones are obtained for the events in the East African Rift, in the considerable exception of the event located close to Tamanrasset in South Algeria, discussed in the following section.

\subsection{Special Case of Tamanrasset Event}

As discussed earlier, this event is very particular because it occurred in the middle of the stable plate, providing a path fully included into the continental plate. Fortunately, the GeoScope French global network operates a station close to Tamanrasset, which has recorded this event. Figure 3 shows time-frequency plots of the records at both stations; they show a well-developed coda ranging to at least $400 \mathrm{~s}$ after the Lg arrival-time for the Chad station, and more than $500 \mathrm{~s}$ for the Tamanrasset station. Finally, Table 3 gives the parameters resulting from the processing. Despite the very different distances of propagation, these results show very similar values for both $Q_{0}$ and $\alpha$. This is a strong indication that our measures of $Q_{0}$ correspond to an averaged value available for 


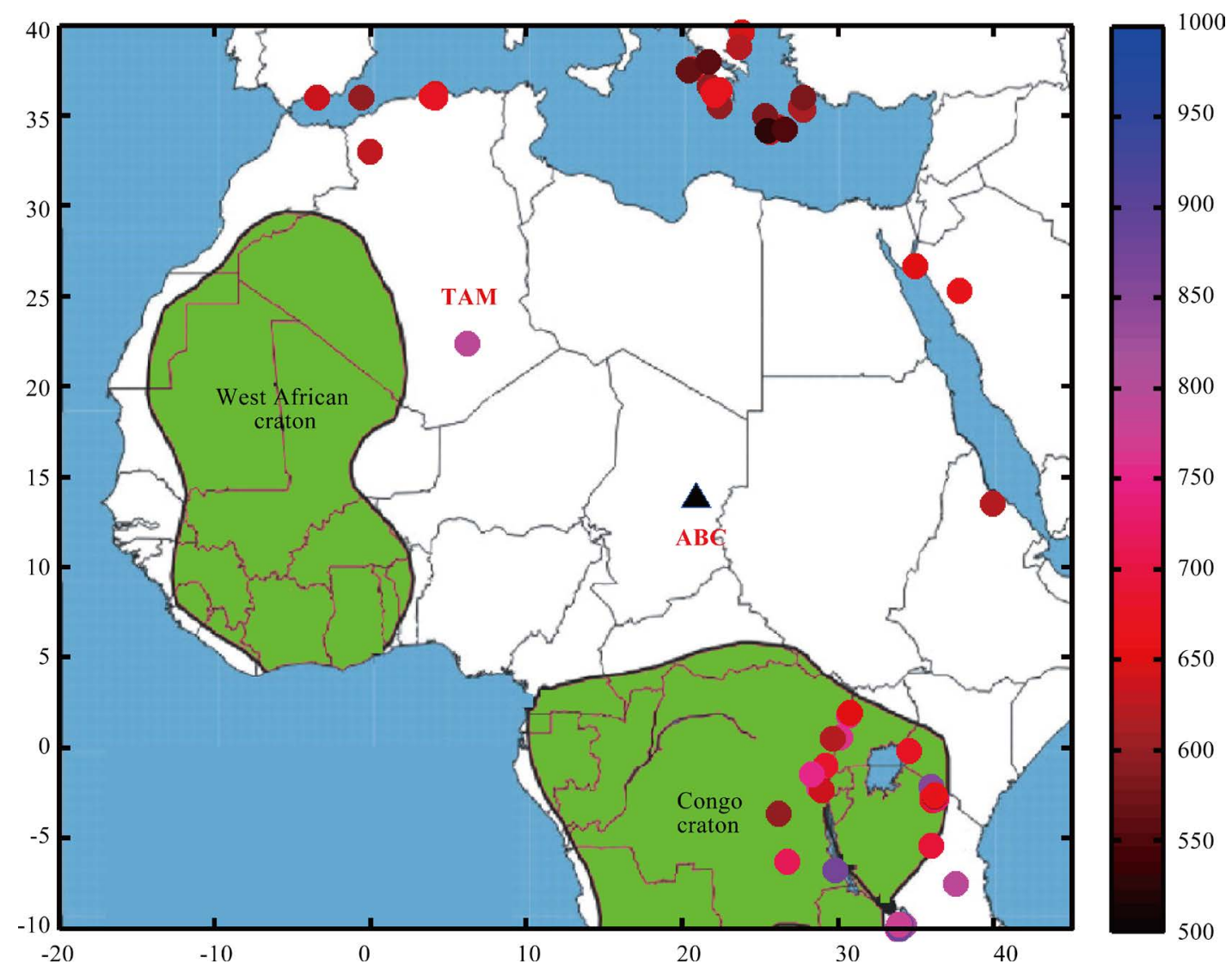

Figure 6. Geographical representation of the $Q_{0}$ factor obtained for each event (color scale).

Table 2. Averaged results for the main regions of interest and for the global dataset.

\begin{tabular}{cccc}
\hline Region & \#Events & Averaged $Q_{0}$ & Averaged $\alpha$ \\
\hline Greece and Turkey & 25 & $617 \pm 34$ & $0.72 \pm 0.4$ \\
East African Rifts & 36 & $690 \pm 42$ & $0.70 \pm 0.2$ \\
Red Sea & 3 & $645 \pm 18$ & $0.70 \pm 0.24$ \\
North Africa & 5 & $650 \pm 18$ & $0.92 \pm 0.21$ \\
Full dataset & 70 & $650 \pm 34$ & $0.77 \pm 0.2$ \\
\hline
\end{tabular}

Table 3. $Q_{0}$ and $\alpha$ parameters obtained for the Tamanrasset earthquake at Chad (ABC) and Tamanrasset (TAM) stations.

\begin{tabular}{cccc}
\hline Station & $Q_{0}$ & $\alpha$ & Epicentral distance $(\Delta \mathrm{km})$ \\
\hline TAM (Z component) & 798.5 & 0.30 & 60 \\
TAM (North component) & 797.56 & 0.29 & \\
TAM (East component) & 798.56 & 0.29 & 1822 \\
ABC (Z component) & 794.2 & 0.31 & \\
\hline
\end{tabular}

the whole stable crust of the northern part of Africa.

\subsection{3-Component Results}

The Chad station in Abéché is equipped with a 3-component seismometer. In this section, we compare results obtained by the coda processing on each component.

Unfortunately, background seismic noise is often higher on horizontal components than on the vertical one. 


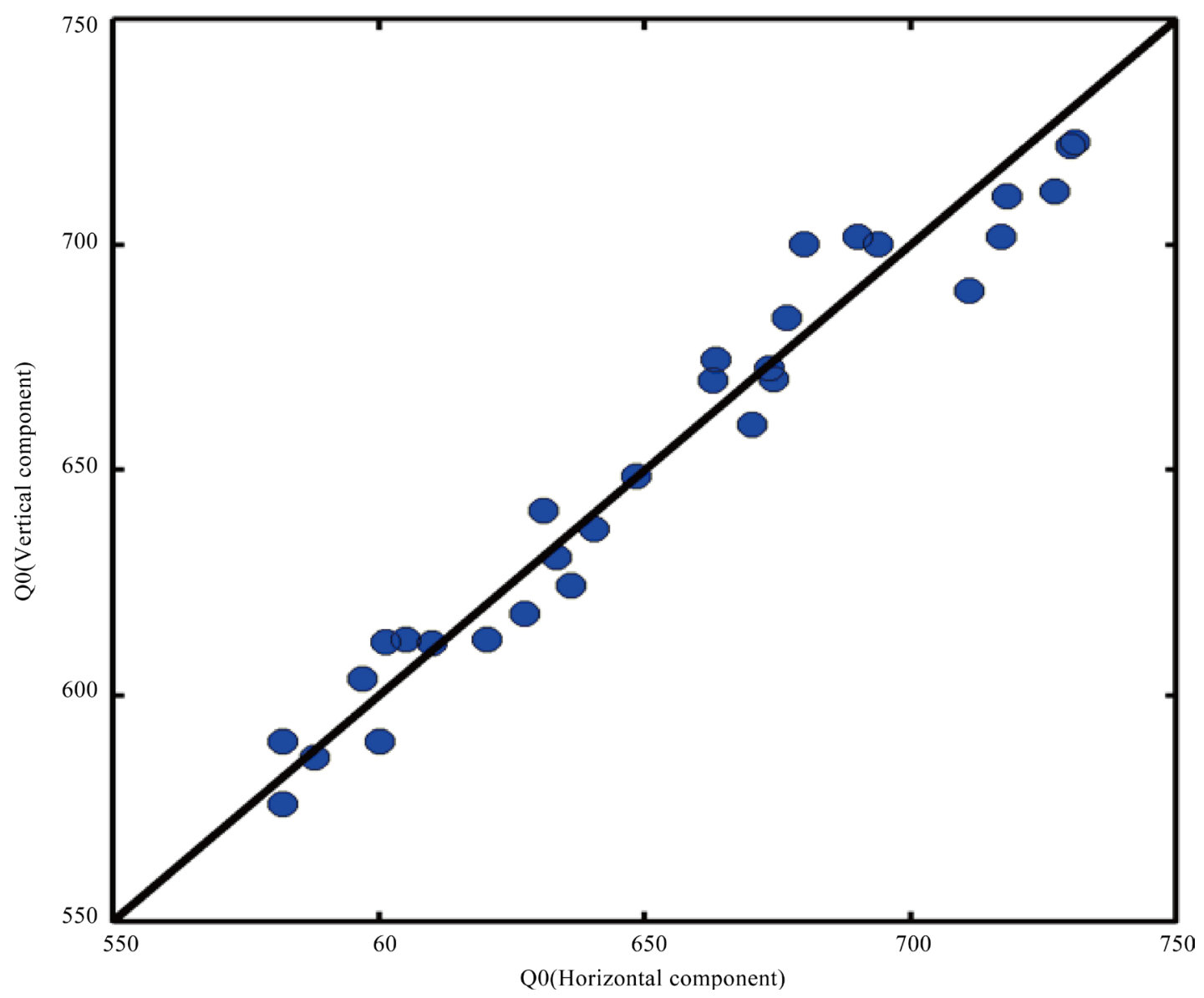

Figure 7. Comparison between $Q_{c}$ computed on the vertical and east components. The black line is the best linear fit assuming crossing 0 .

This leads to a less important dataset; more precisely, only 30 of the original 70 events can be used to compute the horizontal $Q_{c}$ factor. Figure 7 is a plot of the resulting $Q_{0}$ for these events; the black line is the best linear fit assuming crossing 0 ; it leads to an averaged ratio very close to 1 , suggesting that there is no evidence of any difference between vertical and horizontal coda generations.

\subsection{Discussion-Conclusion}

We have taken advantage of the ideal situation of the seismic station ABC (Abeche, Tchad) in the center of the northern part of Africa, which is a quiet seismic area and a very stable tectonic plate. Seismicity is located in the outskirts of the plate, at distances often greater than $1500 \mathrm{~km}$, mainly in the north and east directions. Due to this stability, Lg-waves can propagate in the crust over long distances and are then recorded on the ABC station. Lg-codas are then used to study attenuation of Lg-waves in the crust according to Aki's formulation. For the whole area, we have found a frequency dependence described by the following formula: $Q(f)=(650 \pm 34) f^{(0.77 \pm 0.2)}$ similar values are obtained for the attenuation measured on horizontal components. However, some events lead to lower values indicating higher attenuation; they are located close to South Turkey, which is consistent with the fact that no Lg-waves are recorded at ABC for events located in this area. Finally, the largest value is obtained for an event located in the middle of the place close to the city of Tamanrasset. Using records of the station TAM located close to the event, we obtained a very similar value for the attenuation; this strongly validates that the obtained values represent the attenuation at the global scale.

\section{References}

[1] Aki, K. and Chouet, B. (1975) Origin of Coda Waves: Source, Attenuation, and Scattering Effects. Journal of Geo- 
physical Research, 80, 3322-3342. http://dx.doi.org/10.1029/JB080i023p03322

[2] Woodgold, C.R.D. (1990) Estimation of Q in Eastern Canada Using Coda Waves. Bulletin of the Seismological Society of America April, 80, 411-429.

[3] Zhu, X.-Y. (2014) An Inversion of Lg-Wave Attenuation and Site Response from Seismic Spectral Ratios in the Eastern China Region. Bulletin of the Seismological Society of America, 27, 1389-1399.

[4] Aki, K. (1969) Analysis of the Seismic Coda of Local Earthquakes as Scattered Waves. Journal of Geophysical Research, 74, 615-631. http://dx.doi.org/10.1029/JB074i002p00615

[5] Abubakirov, I.R. and Gusev, A.A. (1990) Estimation of Scattering Properties of Lithosphere of Kamchatka Based on Monte Carlo Simulation of Record Envelope of a Near Earthquake. Physics of the Earth and Planetary Interiors, 64, 52-67. http://dx.doi.org/10.1016/0031-9201(90)90005-I

[6] Hoshiba, M. (1994) Simulation of Coda Wave Envelope in Depth Dependent Scattering and Absorption Structure. Geophysical Research Letters, 21, 2853-2856. http://dx.doi.org/10.1029/94GL02718

[7] Lacombe, C., Campillo, M., Paul, A. and Margerin, L. (2003) Separation of Intrinsic Absorption and Scattering Attenuation from Lg Coda Decay in Central France Using Acoustic Radiative Transfer Theory. Geophysical Journal International, 154, 417-425. http://dx.doi.org/10.1046/j.1365-246X.2003.01976.x

[8] Ekmer, Z., Sandvol, E., Xie, J., Turkeli, N., Mitchell, B., Gasanov, A.H. and Yetirmishli, G. (2007) Crustal Attenuation within Turkish Plateau and Surrounding Regions. Bulletin of the Seismological Society of America, 97, 151-161. http://dx.doi.org/10.1785/0120050227

[9] Calvert, A., Sandvol, E., Seber, D. and Barazangi, D. (2000) Propagation of Regional Seismic Phases (Lg and Sn) and Pn Velocity Structure along the Africa-Iberia Plate Boundary Zone: Tectonic Implications. Geophysical Journal International, 142, 384-408. http://dx.doi.org/10.1046/j.1365-246x.2000.00160.x

[10] Jemberie, A.L. and Nyblade, A.A. (2009) Intrinsic and Scattering Q near $1 \mathrm{~Hz}$ across the East African Plateau. Bulletin of the Seismological Society of America, 99, 3516-3524. http://dx.doi.org/10.1785/0120090062

[11] Ambeh, W.B., Fairhead, J.D. and Francis, D.J. (1989) Coda Q Estimates in the Mount Cameroun Region, West Africa. Journal of African Earth Sciences, 9, 1-7. http://dx.doi.org/10.1016/0899-5362(89)90002-X

[12] Begg, G.C., Griffin, W.L., Natapov, L.M., O’Reilly, S.Y., Grand, S.P., O’Neill, C.J., Hronsky, J.M.A., Poudjom Djomani, Y., Swain, C.J., Deen, T. and Bowden, P. (2009) The Lithospheric Architecture of Africa: Seismic Tomography, Mantle Petrology, and Tectonic Evolution. Geosphere, 5, 23-50. http://dx.doi.org/10.1130/GES00179.1

[13] Guiraud, R., Bosworth, W., Thierry, J. and Delplanque, A. (2005) Phanerozoic Geological Evolution of Northern and Central Africa: An Overview. Journal of African Earth Sciences, 43, 83-143. http://dx.doi.org/10.1016/j.jafrearsci.2005.07.017

[14] Tabod, C.T., Fairhead, J.D., Stuart, G.W., Ateba, B. and Ntepe, N. (1992) Seismicity of the Cameroon Volcanic Line, 1982-1990. Tectonophysics, 212, 303-320. http://dx.doi.org/10.1016/0040-1951(92)90297-J

[15] Saria, E., Calais, E., Altamimi, Z., Willis, P. and Farah, H. (2013) A New Velocity Field for Africa from Combined GPS and DORIS Space Geodetic Solutions: Contribution to the Definition of the African Reference Frame (AFREF). Journal of Geophysical Research: Solid Earth, 118, 1677-1697. http://dx.doi.org/10.1002/jgrb.50137

[16] McClusky, S., Reilinger, R., Ogubazghi, G., Amleson, A., Healeb, B., Vernant, P., Sholan, J., Fisseha, S., Asfaw, L., Bendick, R. and Kogan, L. (2010) Kinematics of the Southern Red Sea-Afar Triple Junction and Implications for Plate Dynamics. Geophysical Research Letters, 37, Article ID: L05301

[17] Stamps, D.S., Calais, E., Saria, E., Hartnady, C., Nocquet, J.-M., Ebinger, C.J. and Fernandes, R.M. (2008) A Kinematic Model for the East African Rift. Geophysical Research Letters, 35, Article ID: L05304. http://dx.doi.org/10.1029/2007GL032781

[18] Peterson, J. (1993) Observations and Modeling of Seismic Background Noise. U.S.G.S, Open File Report, 93-322, 95 p. 